SALVI TURRÓ

Universidad de Barcelona, España

Recibido: 7/01/2015

salvi.turro@ub.edu

Aprobado: 16/02/2015

\title{
"Qué tipo de entidades son necesarias para hacer del mundo un mundo» [A propósito de Enciclopedia \$50]
}

\author{
"What kind of beings are needed to make the \\ world a world» [About Encyclopedia \$ 50]
}

RESUMEN: Se parte de unas consideraciones previas sobre filosofía y mundo para introducir el tema del «acosmismo» con que Hegel califica la posición de Spinoza. Establecida la historia conceptual del término en su contexto inmediato (Wolff, Platner, Maimon), se fija el sentido más relevante de la discusión como contraposición entre distintas formas de entender el «orden del mundo». Seguidamente se procede a reconstruir la comprensión hegeliana del «mundo» en base a las aporías generadas en el nivel del espíritu objetivo y su superación en el nivel del espíritu absoluto. Se puede así contraponer la mundanidad hegeliana a la acosmicidad spinozista como oposición entre una temporalidad «cualitativa» (cristiano-escatológica) y otra meramente extensiva propia del universo homogéneo e isótropo de la nueva ciencia.

\begin{abstract}
Hegel notoriously viewed Spinoza's thought as a form of «acosmism», a topic which is here introduced by way of summoning the link between philosophy and world. Appropriately embedded in a succession of immediate contexts (Wolff, Platner, Maimon), the conceptual history of this notion leads to seeing the controversy surrounding it as a clash between opposite ways of understanding the «order of the world». Thereafter the Hegelian conception of the world is reconstructed along the claim that the absolute spirit overcomes the aporiae contrived by the objective spirit. This circumstance leads to perceive in the collision between Hegelian worldliness and Spinozist acosmicity the pitting of a «qualitative» temporality (of Christian-theological bent)
\end{abstract}


Ello permite, a su vez, situar ambos modelos en el horizonte de la «sabiduría del mundo» de los antiguos y la función de la filosofía como consolatio.

PALABRAS ClAVE: Hegel - SPINOZA - Acosmismo - Mundanidad - ConcepCIÓN DEL MUNDO - SABIDURÍA DEL MUNDO against the merely extensive temporality implied by the homogeneous and isotropic universe of the new science. This outcome, in its turn, suggests ranging both models in the setting deployed by the antique «worldly wisdom» and the commitment to philosophy as «consolatio».

KEYWORDS: HEgEL - SPINOZA - ACOSMISM - WORLDLINESS - CONCEPTION OF THE WORLD - WORLDLY WISDOM

$\mathrm{L}$ A CITA QUE ENCABEZA ESTE TRABAJO pertenece a una carta enviada por Léo Strauss, pocos días antes de su muerte, al teólogo e historiador israelí Gerhard Scholem. El pasaje completo dice así: «Bastante apiquorsic aunque presiento que el Jefe no me condenará, pues es un dios misericordioso y sabe mejor que nosotros qué tipo de entidades son necesarias para hacer del mundo un mundo» ${ }^{1}$. En el texto original figura el término hebreo 'ôlām en lugar de su «equivalente» inglés world. En el marco de la tradición profética hebrea, 'ôlām designaba aquella «edad del mundo» que precede el advenimiento del Reino de Dios, mientras que el término griego кó $̧ \mu$ o designó, desde la generalización de su uso en el siglo V a.C., la totalidad de cuanto hay en el firmamento ${ }^{2}$. Que sentidos tan distintos - uno temporal-proyectivo, otro espacial-natural-, a través de las diversas traducciones y comentarios helenísticos y cristianos, converjan finalmente en el mismo mundus ya muestra una primera problematicidad, al menos «genealógica», del concepto.

Entre los judíos ortodoxos apikorsut -derivado de Epikureertum, epicureísmo- se utiliza peyorativamente para calificar a todo aquel que, desde la racionalidad filosófica, osa criticar el contenido de la Ley y la tradición ${ }^{3}$. Uso este que no deja de ser certero en un punto: entre los filósofos antiguos ciertamente fueron lo epicúreos quienes con mayor radicalidad sometieron a crítica las representaciones religiosas del mundo para sustituirlas por una concepción racionalmente argumentada. Ahora bien, a esta oposición entre el «mundo» teorizado por los filósofos y la tradición, cabe añadir otra no menos significa-

[1] L. Strauss a G. Scholem, 30.IX.1973 (Léo Strauss, Gesammelte Schriften, vol. 3, p. 771).

[2] J. Ritter, K. Gründer y F. Gabriel edts., Historisches Wörterbuch der Philosophie, Darmstadt, WBG Verlag, 1971-2007, vol. XII, p. 407).

[3] Referencia básica al respecto es: Y. MALkin, Epicurus and Apikorsim. The Influence of the Greek Epicurus and Jewish Apikorsim on Judaism, Library of Secular Judaism, Milan Press, 2008. 
tiva: la que hay entre los diversos modelos de «mundo» que la propia reflexión filosófica ha producido, por ejemplo, entre el atomismo antiguo y el universo platónico-aristotélico ${ }^{4}$. De este modo, vista desde un «orden» conceptual determinado, la ordenación alternativa aparece necesariamente como «a-cósmica», «in-munda». Tenemos así una segunda problematicidad, «sistemática» ahora, de tal concepto.

En el plano transcendental: la conciencia, porque es una actividad que, desplegándose a través de lo que se le contrapone, se recupera a sí misma como unidad, tiende necesariamente a aprehender cuanto se le aparece en forma de una totalidad significativa. La conciencia transciende lo dado porque lo recoge (légein), lo articula, lo «ordena». Si en su inmediatez fáctica e histórica tal «impulso mundanizador» da lugar a diversas precomprensiones de la realidad o «visiones del mundo», la filosofía quiere ser la discusión rigurosa y sistemática de su verdad $y$, por tanto, el intento de fundamentar qué sea, con certeza, el «mundo» y las entidades que lo integran ${ }^{5}$. La filosofía es así esencialmente "cosmética»" ${ }^{6}$ : piensa qué y cómo sea el unum que, dando su sentido a lo diverso, lo convierte en pulchrum-bonum. "Cosmética filosófica» que comporta necesariamente dos operaciones: «ordena» en el sentido que construye una totalidad conceptualmente consistente, «embellece» en el sentido que esa construcción, «acondicionando» lo inhóspito y penoso de la realidad, es también consolatio. Tercera problematicidad, pues, entre voluntad de verdad y necesidad de consuelo.

Aunque en Hegel «mundo» no sea un término sistemáticamente relevante, el tema recorre todo su pensamiento, pues siendo la filosofía «saber absoluto» es claro que pretende dar una respuesta fundamentada a la totalidad de lo existente (naturaleza y espíritu). Baste al respecto el ejemplo paradigmático de la Fenomenología del Espíritu: dada la triple dimensión constitutiva de la subjetividad -saber del objeto, saber de sí y saber de lo Absoluto-, cada gran ciclo transversal de figuras de conciencia es un modo de pensar unitariamente la

[4] R. Brague (La sagesse du monde. Histoire de l'expérience humaine de l'univers, Paris, Fayard, 1999), distingue cuatro «sabidurías del mundo» en la antigüedad: platónica o timeica (dentro de la cual se mantendría Aristóteles y el estoicismo), atomista, abrahámica y gnóstica.

[5] Aunque tengan un común origen en la tendencia de la conciencia a unificar todos los ámbitos de su actividad, cabe distinguir estrictamente entre las «cosmovisiones» histórico-culturales -en el sentido que va de Humboldt a Dilthey- y la tarea «científica» de la filosofía por discutir e intentar fundamentar racionalmente la idea de «mundo» o sus posibles modelos pensables. En este sentido, recuérdese la ya clásica crítica de Husserl a las filosofías cosmovisionales de su época en La filosofía como ciencia estricta.

[6] Remitimos a la lectura que L. STRAuss hace de Sócrates y la esencial función «cosmética» de la filosofía en Xenophon's Socratic Discourse: An Interpretation of the Oeconomicus, Cornell UP, 1970. 
experiencia cognoscitiva, las mores e instituciones sociopolíticas y la religiosidad expresada en el arte, esto es, es un modo de pensar un «mundo». En tal sentido, "el camino de la conciencia natural que se abre paso hacia el saber verdadero» ${ }^{7}$ no es otra cosa que la confrontación de diversos modelos de «mundo» hasta llegar a integrarlos en uno absolutamente fundamentado.

En nota al $\$ 50$ de la segunda edición de la Enciclopedia, Hegel, no sólo introduce unas consideraciones relevantes sobre la relación entre el mundo y Dios, sino que se pronuncia explícitamente sobre la filosofía de Spinoza en tanto que «acosmismo». Frente al «reproche que se hace al spinozismo de ser panteísmo y ateísmo» ${ }^{8}$, si se atiende a la afirmación textual de la Ética de que tanto el pensamiento como la extensión son atributos de la única substancia, resulta que el Deus sive Natura habría de calificarse de otro modo:

«Aun prescindiendo de que Spinoza no define Dios como la unidad de Dios y del mundo sino como la unidad del pensar y de la extensión (el mundo material), en esta unidad ya radica -aunque sea tomada de aquel primer modo totalmente inadecuado [como substancia absoluta y no como espíritu absoluto]- que en el sistema spinozista se determina el mundo más bien sólo como un fenómeno carente de realidad efectiva, de modo que este sistema ha de considerarse más bien como un acosmismo. Al menos, una filosofía que afirma que Dios y sólo Dios es, no debería presentarse como ateísmo»?

Esta valoración del spinozismo como «acosmismo», aun no teniendo demasiadas ocurrencias en el corpus hegeliano ${ }^{10}$, parece expresar sin embargo una

[7] Phänomenologie des Geistes [PhG] (GW, IX, 55). Referimos las obras de Hegel según las abreviaturas indicadas en la primera cita. Siempre que es posible citamos por los Gesammelte Werke [GW] (Deustchen Forschungsgemeinschaft, Rheinisch-Westfäslischen Akademie der Wissenschaften, Hamburg, Meiner, 1968 ss.); cuando ello no es posible, citamos por las ediciones más usuales: la reimpresión en 20 volúmenes de la edición de los discípulos, a cargo de $\mathrm{E}$. Moldenhauer y K.M. Michel en Suhrkamp Verlag, 1970 en la colección Theorie Werkausgabe [referenciada por: TWA]; y los volúmenes con aparato crítico de Meiner Verlag en la serie Philosophisches Bibliotek [referenciada por: $\mathrm{MPhB}$ ]. En todos los casos, el volumen se indica en cifras romanas y la página en árabe.

[8] Enziklopedie der philosophischen Wissenschaften im Grundrisse [Enz.], $₫ 50$ Anm. (GW, XX, 89).

[9] Ibid.

[10] En la versión informática de la edición de los discípulos (G.W.F. Hegel Werke, Hegel-Institut Berlin, Talpa-Verlag, 2000), sólo se localizan ocho ocurrencias del término en las variantes de: Akosmismus, Akosmisten o Akosmismen. Cuatro en la Enciclopedia: la citada nota del $\$ 50$; dos veces en el Zusatz de Enciclopedia $\$ 151$ (TWA, VIII, 296) -mera retiración de la nota anterior-; y una vez en la nota del $\$ 573$ (GW, XX, 564-565), donde el término se aplica a Spinoza y a los eleáticos. Las otras cuatro ocurrencias se encuentran en el capítulo dedicado a 
reflexión muy madura y en cierto modo «definitiva» de Hegel: ni se halla en los textos juveniles ni aparece tampoco en la primera edición de la Enciclopedia de 1817, para figurar por primera vez en la segunda edición de 1827 y mantenerse inalterada en la tercera de 1830 . Además, es la tesis que aplica también en su exposición de Spinoza en las Lecciones de historia de la filosofía, donde aparece el término exactamente en el mismo sentido y con la misma argumentación que en el pasaje citado de la Enciclopedia. Se trata, pues, de una reflexión específica del período de Berlín y, por tanto, del sistema en su versión final.

Pues bien, que (filosóficamente) pueda sostenerse que no hay «mundo» no parece una afirmación trivial sino lo suficiente relevante como para hacer de ella el eje de una comparación entre Hegel y Spinoza, y quizá incluso la vía de acceso a ciertos supuestos esenciales del pensamiento hegeliano. Tales serán los dos objetivos de este artículo.

De entrada, al contraponer el término «acosmismo» a los calificativos de panteísmo y ateísmo, Hegel se sitúa explícitamente en relación al Spinozismusstreit. Esta polémica, aunque suele centrarse en los efectos desencadenados por las Cartas a M. Mendelssohn sobre la filosofía de Spinoza publicadas por Jacobi en 1785, de hecho tiene una historia mucho más prolongada ${ }^{11}$, de la que ni la noción ni incluso la expresión literal de «acosmismo» está ausente. Detallemos los momentos centrales que configuran esta historia conceptual previa a la reflexión hegeliana ${ }^{12}$.

1744: a la traducción alemana de la Ética se añade, a modo de apéndice, la Refutación de la doctrina moral de Spinoza por el «sabio de fama mundial de nuestra época, Ch. Wolff» ${ }^{13}$. Dos son los núcleos de esta crítica. En el plano estrictamente metafísico, los equívocos denunciados por Wolff entre las nociones

Spinoza de las Lecciones de historia de la filosofía (TWA, XX, 163, 177, 191, 195).

[11] Véase un recorrido sumario por tal historia en: J. Solé, Spinoza en Alemania (16701789), Córdoba (Argentina), Buenos Aires, 2011.

[12] En los Gesammelte Werke se señalan, en las notas críticas de la Enciclopedia $\$$ 50, tres precedentes de la posición hegeliana: Maimon y Fichte en nota al volumen de la edición de 1827, y Wolff en nota a la edición de 1830. Las tres referencias han sido recogidas por R. Valls en la nota 185 de su traducción de la Enciclopedia (Madrid, Alianza, 1997). Nosotros añadimos aquí la importante aportación de Platner no citada en las aquellas ediciones. Prescindimos, empero, de referirnos al caso de Fichte, pues el pasaje en que utiliza el término «acosmismo» no hace referencia a Spinoza sino que sólo tiene un sentido apologético -seguramente a partir de la lectura de Maimon- para replicar a la acusación de ateísmo: «Si piensa darme un nuevo nombre, que me llame p. ej. acosmista, pero no ateo» (Fichte, Escritos de justificación jurídica; GA, I/6, p. 54).

[13] Ch. Wolff, Gesammelte Werken (Sección III, volumen 15), Georg Olms Verlag, Hildesheim, 1981. 
de substancia, atributos y modos permiten subrayar cómo la tesis de la existencia de una substancia única comporta finalmente que «Spinoza convierte el poder de la naturaleza en poder de Dios y elimina la naturaleza propiamente dicha de los cuerpos en los que consiste el mundo, es decir, convierte la naturaleza propiamente dicha en un absurdo (Unding)» ${ }^{14}$. Por otro lado, Wolff denuncia el spinozismo como un determinismo fatalista tal que, al negar las causas finales y los milagros, conduce necesariamente a la irreligiosidad y a negar los mandamientos divinos: argumentos todos estos que, sin demasiadas innovaciones, explotará hábilmente Jacobi cuarenta años después. El balance final de Wolff no puede ser más desfavorable: «el spinozismo no se aleja demasiado de la negación de Dios y es tan dañino como ella: más aún, en cierto sentido es aún más dañino que negar a Dios» ${ }^{15}$. En suma, si bien Wolff no llega a sostener abiertamente el ateísmo de Spinoza -como sí hará Jacobi-, establece en cambio la doble negación del «mundo» que se opera en su filosofía: como naturaleza independiente y como orden teleológico-religioso-moral.

1776: Platner publica sus Aforismos filosóficos ${ }^{16}$, obra de gran difusión en la Ilustración alemana y cuya segunda edición utilizará Fichte en su curso de 1798 sobre la existencia de Dios y la inmortalidad del alma -del que derivará precisamente el Atheismusstreit. El $\S 977$ de los Aforismos, entre los «tres sistemas ateístas respecto a la causa eficiente de la totalidad el mundo» ${ }^{17}$, sitúa el de Spinoza cuya tesis central considera «la totalidad del mundo [como] modificaciones de una única substancia» $»^{18}$. Ahora bien, cuando pasa a analizar las primeras tesis de la Ética, Platner se ve obligado a matizar la caracterización inicial de ateísmo, pues «Spinoza no niega propiamente la existencia de la divinidad sino la existencia del mundo, pues no hay en su sistema nada real más que Dios, es decir, el ser eterno infinito» ${ }^{19}$. A su vez, como la inexistencia (substantiva) del mundo significa reducirlo a modificaciones del ser divino y éstas se siguen según un orden necesario, resulta igualmente imposible sostener una ordenación teleológica de la realidad: «Dios es así la única substancia y el mundo es la serie infinita de accidentes, yuxtapuestos y sucesivos, existentes en Dios según necesidad expresa y sin ninguna causa final $»^{20}$. Sin embargo, llegados a este punto, Platner se aparta de concluir con Wolff la peligrosidad moral de Spinoza. Al final de su exposición tiene lugar un cambio de regis-

[14] Ibid., $\$ 696$.

[15] Ibid., $\$ 716$.

[16] Ernst Platners philosophische Aphorismen nebst einigen Anleitungen zur philosophischen Geschichte, Leipzig, Swickertschen Verlag, 1776.

[17] Ibid., p. 352.

[18] Ibid., p. 352.

[19] Ibid., p. 353.

[20] Ibid., p. 353-354. 
tro sorprendente quizá para nosotros, pero usual en la ilustración moderada berlinesa de la época: en la línea interpretativa de Mendelssohn, Platner acaba por afirmar que, como los modos y su sucesión causal son inmanentes a la divinidad, «el mundo de Spinoza es un mundo ideal cuyo plan del mundo desde el inicio de las cosas, como en el sistema leibniziano, existe solamente en el entendimiento divino» ${ }^{21}$. Atribuyendo a Dios un entendimiento en acto, Platner abre la vía de «remundanizar» teleológicamente la realidad, pues «aquí es donde Spinoza ha preparado el sistema de la armonía ${ }^{22}$ : la concordancia leibniziana entre causas eficientes y finales, reino de la naturaleza y la gracia, la unidad físico-moral del mundo ${ }^{23}$.

1792: Maimon, en su Biografía ${ }^{24}$, recoge las argumentaciones anteriores dando el último paso terminológico. Dado que «el sistema spinozista supone una y la misma substancia como causa inmediata de todos los diversos efectos, que han de ser considerados como predicados de uno y el mismo sujeto", propiamente sólo hay «un único ser subsistente por sí mismo» de manera que «todos los así llamados seres fuera de él son sus modos» ${ }^{25}$. De donde la conclusión es obligada: «es inconcebible cómo se ha podido hacer del sistema spinozista un ateísmo, pues ambos se oponen del todo. En éste es negada la existencia de Dios, mientras que en aquél la existencia del mundo. Por tanto, habría de llamársele más bien un sistema acósmico» ${ }^{26}$. Además de la aportación terminológica, es conveniente señalar el contexto en que Maimon desarrolla su reflexión y que acaba de darle su pleno sentido: el pasaje citado es una breve digresión intercalada en un capítulo mucho más amplio destinado a presentar «una breve historia pragmática de la religión judía ${ }^{27}$. ¿Qué implica esta ubicación? Analizando el judaísmo a la luz de los distintos aspectos que toda religión comporta (natural, positivo, político), Maimon muestra tanto su con-

[21] Ibid., p. 355.

[22] Ibid., p. 354

[23] Quizá por esta doble perspectiva interpretativa difícilmente conciliable -máxime después de la publicación de Jacobi de 1785-, en la segunda edición de los Aforismos (1793), Platner se limita a exponer $(\$ 754)$ con suma literalidad las tesis metafísicas de la Ética, añadiendo a continuación $(\$ 755)$ unas consideraciones críticas en las que reconoce que «antes tuve la presunción de querer entender el sistema de Spinoza [...], pero después de muchos años [...] en mi opinión la Ética de Spinoza es un libro completamente incomprensible. Incluso cuando leo la exposición maestra del Sr. Jacobi, siempre dudo si penetro en las ideas profundamente pensadas, en los giros originales de razones y consecuencias, en el curso del pensamiento de Spinoza o de su epitomador» (Platner, Philosophische Aphorismen, $2^{\mathrm{a}}$ ed., 1793, vol. I; reeditado en: Fichte; GA, II/4S, p. 199-200).

[24] Salomon Maimon's Lebensgeschichte in zwei Theilen, Berlin, Friedrich Bieweg, 1792.

[25] Ibid., p. 153.

[26] Ibid., p. 154

[27] Ibid., p. 150 
cordancia con los principios de la religión natural como su función al servicio del orden social y estatal ${ }^{28}$. La estrategia de Maimon es sutil: si Spinoza no es ateo sino sólo acosmista, puede entonces ser reintegrado a la tradición judía y su sistema ser compatible con la religión -al menos la religión racional, en la línea de Mendelssohn- y con su cometido ordenador teológico-político. Como en el caso de Platner, pero con una estrategia distinta, también Spinoza queda finalmente exonerado de inmoralidad o negación del orden social.

Es claro, pues, que el pronunciamiento de Hegel sobre Spinoza en Enciclopedia $\$ 50$ tiene una situación dialógica muy determinada: no sólo en relación a la posición de Jacobi y su acusación de panteísmo-ateísmo, sino tanto o más en relación a la discusión desarrollada por Wolff, Platner y Maimon sobre el «acosmismo». Concepto este que, como acabamos de reconstruir históricamente, contiene en sí mismo una tensión interna entre los dos sentidos posibles del «mundo» (el metafísico y el moral-teolológico-político) y la unidad última que parece exigir tal concepto. Tensión, problematicidad o dialéctica a la que pretende responder la comprensión hegeliana del «mundo» en tanto que diálogo, asunción y crítica de Spinoza.

De lo anterior se desprende un primer dato relevante: que la tematización del «acosmismo» se plantea en estricta correlación con la cuestión teológica, esto es, qué sea el «mundo» en sentido fuerte sólo puede responderse (en una forma u otra) si se responde simultáneamente al tema de Dios. Tal reciprocidad explica el lugar que ocupa el pasaje citado de la Enciclopedia: en la nota al § 50 que trata sobre los «dos caminos o formas» ${ }^{29}$ para alcanzar el tercer incondicionado. Como el primer camino (a posteriori) parte de «lo inmediato en tanto que un ser determinado de modo infinitamente diverso, de un mundo pleno» ${ }^{30}$, se entiende que sea el lugar adecuado para incluir aquella observación sobre el acosmismo. Pues bien, Hegel la concluye diciendo:

«Suponer algo así como que no hay mundo, o como se quiera expresar, se considera fácilmente como algo del todo imposible o, al menos, por bastante menos posible que pueda a alguien pasarle por la cabeza que no hay Dios. Se cree más fácilmente - y ello no para el honor propio- que un sistema niegue a Dios que al mundo; se encuentra más concebible que sea negado Dios que el mundo» ${ }^{31}$.

[28] Ibid., p. 155 ss.

[29] Enz. \$ $50(\mathrm{GW}, \mathrm{XX}, 86)$.

[30] Ibid.

[31] Enz. $\$ 50$ Anm. (GW, XX, 89). 
En este pasaje, no sin cierta ironía, de hecho Hegel descarta un primer sentido de acosmismo. ¿Desde dónde argumenta la conciencia -pretendidamente devota- que antes se escandaliza de que alguien niegue el mundo que a Dios? Sólo puede tratarse de la conciencia natural que apela a la certeza sensible como testimonio infalible contra tal negación -igual que su devoción remite a la pretendida inmediatez del sentimiento-: para quien el hic et nunc-el darse del datum en su mero darse- es lo únicamente real y verdadero, difícilmente duda de ello, antes duda de Dios. Pero tal figura, como quedó de manifiesto en la Fenomenología, incurre en clara contradicción performativa, pues para enunciar su tesis tiene que presuponer ya la validez de algo que, no sólo no es «dado», sino que constituye el elemento más opuesto a todo darse empírico-particular: el poder universalizador del lenguaje. Respecto a nuestro tema: quien dice no poder pensar la negación del mundo (sensible) o bien es porque no piensa en absoluto - pero entonces su fenomenismo radical le ha de llevar consecuentemente al silencio más completo, pues «en el lenguaje nosotros mismos contradecimos inmediatamente nuestra opinión $»^{32}$-, o bien es porque ya está haciendo de sus impresiones inmediatas una cierta totalidad de sentido -«mundo»- con lo cual -sin reconocerlo explícitamente- presupone más de lo que afirma decir desde la sola experiencia.

La nota enlaza así directamente con el final del texto del \$50: «el ascenso del pensamiento de las representaciones empíricas del mundo a Dios se contrapone asíla perspectiva de Hume [...], perspectiva que declara improcedente pensar las representaciones, es decir, extraer de ellas lo universal y necesario " ${ }^{33}$. Pero como «la conciencia es para sí misma su concepto y así inmediatamente un ir más allá de lo limitado» ${ }^{34}$, Hegel puede añadir: «siendo el hombre un ser pensante, ni el sano entendimiento humano ni la filosofía nunca aceptarán que haya de elevarse a Dios desde y a partir de las representaciones empíricas del mundo» ${ }^{35}$. Efectivamente, las pruebas a posteriori, por más que afirmen partir sólo de lo fáctico, en tanto que razonamientos o argumentaciones, son ya un producto del pensar y «pensar el mundo empírico significa más bien y esencialmente alterar su forma empírica y transformarla en un universal» ${ }^{36}$. De hecho tales pruebas no parten propiamente de meros datos, sino que «el punto de partida es ciertamente una visión del mundo determinada de algún modo como un agregado de contingencias o de fines y relaciones finales ${ }^{37}$. Si

[32] $\mathrm{PhG}(\mathrm{GW}, \mathrm{IX}, 65)$.

[33] Enz. $\$ 50(\mathrm{GW}, \mathrm{XX}, 86-87)$.

[34] $\mathrm{PhG}$ (GW, IX, 57).

[35] Enz. \$ 50 Anm. (GW, XX, 87).

[36] Ibid. (GW, XX, 87-88).

[37] Ibid. (GW, XX, 87). 
esas pruebas tienen alguna insuficiencia a los ojos de Hegel, no consiste tanto en que pretendan elevarse a Dios, sino en que «no expresan el momento de la negación contenido en esta elevación ${ }^{38}$, esto es, no reconocen que en su punto de partida (mundo, naturaleza) se está negando la realidad de lo puramente sensible como tal. En suma, toda noción de «mundo» es siempre una negación de lo pretendidamente inmediato o, dicho positivamente, está mediatizada por el pensar. Por ello, no es el filósofo -desde luego no Hegel, pero tampoco Platner ni Maimon- quien se escandaliza porque alguien niegue el mundo en este sentido lato, sino el hombre situado (supuestamente) en la sola certeza sensible, ya que el verdadero filósofo sabe que el «mundo» nunca consiste en la simple inmediatez de lo dado.

Por tanto, que Spinoza sea tildado de «acosmista» significa que elabora una idea de «mundo» donde el estatuto de los objetos naturales y las acciones humanas en relación con lo divino dejan de tener la configuración que tenía en la metafísica anterior -causas segundas subordinadas (eficiente y teleológicamente) a la causa primera- para adoptar otra radicalmente distinta: su «mundo» es un «no-mundo» en la medida que niega el orden humano-divino consagrado en la tradición escolástica -el «universo timeico $»^{39}$ - y convertido en cosmovisión de la conciencia cristiana común hasta bien entrada la modernidad. Desde esta perspectiva hermenéutica, el «acosmismo» atribuido a Spinoza no consiste tanto en negar el «mundo» en abstracto, cuanto en una comprensión de lo natural, lo humano y lo divino que (1) niega la ordenación del mundo propia del «universo timeico», y que (2), de un modo u otro, niega y es negada por la ordenación hegeliana, que constituiría así una réplica a ella.

\section{IV}

En la primera parte de la nota a Enciclopedia $\$ 50$, Hegel ha analizado el aspecto «formal» de las vías a posteriori para «elevarnos a Dios», lo que nos

[38] Ibid. (GW, XX, 88).

[39] «Es con él [Timeo] que la palabra kósmos se ha instalado de manera definitiva y sin ambigüedad en su sentido de 'mundo' [...]. El Timeo pone en funcionamiento el concepto de kosmos suministrando la primera descripción de la realidad formando un todo ordenado, a la vez bueno y bello» (R. Brague, op. cit., p. 35). Este modelo de «mundo», al integrar en su seno el elemento abrahámico, acabaría configurando el modelo dominante en la Edad Media para las tres religiones monoteístas: «no es sólo una descripción estática de la realidad en su estructura jerárquica. Contiene también un modelo de práctica moral. La llamada al buen orden de los fenómenos celestes no es únicamente teórica. Es al mismo tiempo una figura de lo que se exige al hombre, el más noble de los seres relegados a la contingencia de lo sublunar. El orden del mundo superior es el modelo de la conducta correcta de la vida. Es por imitación de la regularidad perfecta de los recorridos celestiales que el hombre podrá tener éxito en poner orden en su propia vida sublunar» (Ibid., p. 153). 
ha permitido rastrear los problemas inherentes al concepto de «mundo» en general. En la segunda parte de la nota se ocupa de la vertiente «material» del tema, es decir, qué entienden aquellas vías concretamente por «mundo» y si tal comprensión es suficiente o no para alcanzar el ser divino. El juicio crítico de Hegel sobre la cuestión resulta útil para determinar qué «entidades» configuran o no, y con qué límites, el «orden del mundo» para el filósofo.

De forma sucinta pero clara Hegel señala el modo tradicional para pasar de la «substancia del mundo» a una «causa rectora y ordenadora según fines»: por reflexión sobre «las cosas del mundo meramente contingentes» o sobre «las configuraciones orgánicas y sus determinaciones finales [que] pertenecen al círculo superior de la vida» ${ }^{40}$. Si una consideración concluye una primera causa, la otra afirma la existencia de una vida divina e inteligente. Pues bien, ninguno de ambos razonamientos es para Hegel «adecuado para lo que se entiende o ha de entenderse por Dios» ${ }^{41}$ :

1. Considerar el mundo como un conjunto de entidades contingentes «es una determinación muy abstracta» ${ }^{42}$. En efecto, ¿qué se entiende concretamente por "contingencia»? ¿Se entiende -modelo timeico vía Aristóteles- que todo movimiento depende de otro y, entonces, la conclusión postula un motor inmóvil? ¿Se entiende, por el contrario, la disposición inercial de la materia -nueva ciencia- y entonces la serie de "causas transitivas» entre los modos podría ser perfectamente infinita sin necesidad de un primer elemento de la serie, como arguye Spinoza ${ }^{43}$ ?

2. Considerar la naturaleza como sistema teleológico que culmina en los seres vivos -Naturphilosophie schellingniana- presenta indudables problemas de justificación racional y de estatuto discursivo. Hegel se hace eco aquí de la crítica moderna al abuso antropomórfico del concepto de «finalidad extrínseca», de modo que lo que parece sugerir de elevado la «contemplación de la naturaleza viva» al final "puede quedar manchado por la insignificancia de los fines o por la mención pueril de ciertos fines y sus relaciones» ${ }^{44}$. Y respecto a considerar el

[40] Enz. \$50 Anm. (GW, XX, 90).

[41] Ibid.

[42] Ibid.

[43] «Toda cosa singular - esto es, toda cosa finita y que tiene una existencia determinadano puede existir ni puede ser determinada a obrar si no es determinada a existir y a obrar por otra causa que también es finita y tiene una existencia determinada, que a su vez tampoco puede existir ni ser determinada a obrar si no es determinada a existir y a obrar por otra que también es finita y tiene una causa determinada y así al infinito» (Ethica, I, prop. XXVIII). Por lo cual, «Dios es causa inmanente -pero no transitiva- de todas las cosas» (Ethica I, prop. XVIII).

[44] Enz. $\$ 50$ Anm. (GW, XX, 90). 
todo de la naturaleza como un gran sistema teleológico-orgánico, las diversas interpretaciones a que da lugar (hylozoismo, pampsiquismo, alma del mundo, gran animal, etc.) son suficientes para concluir que «la naturaleza viviente misma tampoco es de hecho aquello que permite aprehender la verdadera determinación de la idea de Dios» ${ }^{45}$.

Dado que, como decíamos más arriba, hay una indudable reciprocidad entre la idea de mundo y de Dios, sostener que ni una consideración genéricamente contingente de la naturaleza ni una finalístico-orgánica son adecuadas para elevarnos a la «verdadera determinación» de la divinidad equivale a decir que, por sí solas, tampoco permiten pensar propiamente un «mundo ordenado». Ciertamente, más adelante, en los capítulos dedicados a la "filosofía real», la Enciclopedia expondrá la naturaleza como siendo «en sí un todo viviente» cuyo movimiento se produce según un «sucesión de grados» ${ }^{46}$-desde la simple materia mecánica, al organismo pasando por la entidad física ${ }^{47}$,- pero tal consideración, según el orden de razones hegeliano, sólo es posible después que hemos alcanzado la idea del Absoluto y que, desde tal «concepto», «se ha derivado la naturaleza como la idea en la forma del ser-otro» ${ }^{48}$. Antes de ello y al margen de tal comprensión, hay que reconocer que la naturaleza teleológica del universo timeico no tendría por sí misma ninguna relevancia entitativa para Hegel ${ }^{49}$.

Si el «orden del mundo» no se juega esencial ni exclusivamente en concebir la naturaleza por su configuración material-dinámica ni tan siquiera teleológica, ¿dónde tiene su asiento propiamente tal idea y en qué sentido el «mundo» puede ser una vía de elevación a lo divino? La respuesta se indica al final de la nota al $\$ 50$ : «Dios es más que algo vivo, es espíritu. Solo la naturaleza espiritual es el punto de partida más digno y más verdadero para pensar lo Absoluto» ${ }^{50}$. Este final enlaza directamente con los primeros párrafos del $\$ 552^{51}$. Como Kant vio en la Dialéctica de la segunda crítica -aunque lo expresara deficientemente con su doctrina de los postulados-, sólo la praxis, en tanto que actividad espiritual, ofrece una vía de acceso adecuada al Absoluto:

[45] Ibid.

[46] Enz. $\$ 251(\mathrm{GW}, \mathrm{XX}, 241)$.

[47] Enz. \$252 (GW, XX, 241-242).

[48] Enz. $\$ 247$ (GW, XX, 237).

[49] «Si se parte de fines particulares y finitos, por un lado se hace de éstos presuposiciones cuyo contenido accidental puede ser por sí mismo insignificante e inane; por otro lado, la relación final exige por sí un modo de aprehensión más profundo que según relaciones externas y finitas: a saber, el modo de consideración del concepto, el cual, según su naturaleza en general, es inmanente -y con él la naturaleza como tal» (Enz. \$245; GW, XX, 235).

[50] Enz. $\$ 50$ Anm. (GW, XX, 90).

[51] Véase R. Valls en la nota 186 a su traducción de la Enciclopedia (Madrid, Alianza, 1997). 
«El punto de partida contiene implícitamente el contenido o material que constituye el contenido del concepto de Dios. El concreto material verdadero no es, empero, el ser (como en la prueba cosmológica), ni tampoco la actividad según fines (como en la prueba físico-teológica), sino el espíritu, cuya determinación absoluta es la razón eficiente, es decir, el mismo concepto que se determina y se realiza, la libertad» $»^{52}$.

El espíritu es ciertamente identidad consigo mismo, pero tal identidad -momento meramente «formal» de la autoconciencia- sólo puede efectuarse («realmente») a través de lo distinto de ella. Aquello que, en primer lugar, se opone al sujeto como su negación radical es el objeto (naturaleza). Pero justamente por la reflexividad esencial al espíritu, a través de su actividad (trabajo, ciencia, técnica) el objeto es apropiado y reintegrado a la subjetividad, que así se reconoce a sí misma a través de lo otro-natural ${ }^{53}$. Ahora bien, porque el espíritu finalmente ha de encontrarse plenamente a sí mismo, la conciencia precisa del encuentro con otro-yo para que "la unidad de sí misma con su ser-otro» ${ }^{54}$ sea plena recuperación material de su identidad formal, pues ese «ser-otro» es la única alteridad que puede devolverle plenamente su imagen: otra subjetividad libre. Con lo cual alcanzamos el concepto completo de espíritu como intersubjetividad que tiene en el reconocimiento y la reconciliación de sus miembros tanto el motor como la meta de su desarrollo.

El «mundo» es así resultado del espíritu, y las entidades que lo pueblan productos de su actividad: el mundo natural como «supuesto» ya siempre «encontrado previamente» sobre lo que operar; el mundo social como construcción de las mediaciones institucionales necesarias para la reconciliación. Y como el espíritu, a través de sus productos, tiende a reconocerse a sí mismo en su máxima perfección y pureza, el «mundo» es a la vez el lugar de su realización y de su liberación como retorno a sí:

«Las distintas etapas de esta actividad [del espíritu] -al ser la destinación del espíritu finito demorarse en ellas (como aparecer) y recorrerlas- son las etapas de su liberación, en cuya verdad absoluta el previo encontrarse de un mundo como

[52] Enz. \$552 Anm. (GW, XX, 530).

[53] «Para nosotros, el espíritu tiene la naturaleza como su presuposición, siendo su verdad y, por tanto, lo absolutamente primero de ella. En esta verdad la naturaleza ha desaparecido y ha surgido el espíritu como la idea que ha alcanzado su ser-para-sí, cuyo objeto -igualmente en tanto que sujeto- es el concepto. Esta identidad es la absoluta negatividad, pues en la naturaleza el concepto tiene su completa objetividad exterior, pero esta exteriorización suya ha sido superada y en ella se ha hecho idéntico a sí mismo. Es, pues, a la vez esta identidad sólo como retorno a partir de la naturaleza» (Enz. $\$ 381 ; \mathrm{GW}, \mathrm{XX}, 381-382$ ).

[54] PhG (GW, IX, 108). 
mundo supuesto, el engendrarlo como un mundo puesto por él y el liberarse de él en él son una y la misma cosa» ${ }^{55}$.

De aquí se desprende la equivalencia estricta entre «mundo»e «historia». Que el «orden del mundo» sea esencialmente «histórico» no es una mera afirmación antropológica o culturalmente condicionada como en los historicismos decimonónicos, sino una tesis racional que articula de jure la «lógica» de la realidad ${ }^{56}$ : con ello expresa Hegel que todo cuanto es pensable sólo puede determinarse desde la sucesión de estratos conceptuales -naturaleza, espíritu subjetivo, formaciones del espíritu objetivo, etc.- fundados en la actividad automanifestativa del espíritu. Justamente porque esta exigencia «conceptual» determina toda realidad posible, puede afirmarse que «la razón domina el mundo y que, por tanto, también la historia del mundo ha acaecido racionalmente» ${ }^{57}$ y así construir la filosofía de la historia correspondiente. "Mundo» es, pues, el proceso por el cual el espíritu (en sí) se despliega, a través de la serie de sus configuraciones, para alcanzar (para sí) la plenitud de su contenido, esto es, el hacerse del espíritu como «historia»:

«Este movimiento [historia general del mundo] es el camino de liberación de la substancia espiritual, la acción por la que el fin final absoluto del mundo se ejecuta en el mundo. El espíritu, siendo primero sólo en sí, se eleva a la conciencia y a la autoconciencia y, por tanto, a la revelación y efectividad de su esencia en y para sí, y también se convierte en universal exteriormente, en espíritu del mundo» ${ }^{58}$.

Atendamos a este "fin final absoluto del mundo en el mundo». Siendo la historia el movimiento por el que el espíritu se realiza a través de sus mediaciones, tal proceso tiende necesariamente a un «fin final» (Endzweck): término que, desde la discusión kantiana sobre el Juicio teleológico ${ }^{59}$, no indica un

[55] Enz. \$ 386 (GW, XX, 384).

[56] En palabras de Theunissen: «El espíritu, como tema omnicomprensivo de la filosofía de Hegel, es inherente a tal dialéctica porque es historia o -con el término ahora introducidoactividad, y ciertamente 'absoluta actividad' que no es nada más allá de ella y que no procede de ningún sujeto en reposo. Con ello, Hegel muestra que interpreta el espíritu como historia del mismo modo que, a la inversa, la historia como espíritu [... . . Allí donde Hegel, en la Enciclopedia, menciona el 'espíritu y la historia' uno junto a otro, rechaza el pensamiento erróneo de una separación, pues añade que la historia es solamente historia del espíritu» (Hegels Lehre vom absoluten Geist als theologhisch-politischer Traktat, Berlín, De Gruyter, 1970, p. 65).

[57] Vorlesungen über die Philosophie der Geschichte [VorlPhG] (MPhB, I, 28).

[58] Enz. \$549 (GW, XX, 524).

[59] Kant, KU, \$\$81-84. Para una exposición detallada de la problemática en Kant, véase: S. Turró, Tránsito de la naturaleza a la historia en la filosofía de Kant, Barcelona, Anthropos, 1996, pp. 177-190. 
mero «fin último» (letzter Zweck) en la jerarquía de los seres y fines naturales -como en el universo timeico- sino «aquel fin que no necesita ningún otro como condición de su posibilidad $»^{60}$, y que no puede ser otro que «el hombre, pero sólo en tanto que sujeto de moralidad $\aleph^{61}$. En este punto Hegel recupera lo esencial de la "visión moral del mundo» (moralische Weltanschauung) de la Fenomenología: la necesaria unidad entre naturaleza, subjetividad y moralidad como único fin final pensable. Pero tal recuperación se hace corrigiendo las insuficiencias que hacían de la comprensión kantiana «un nido entero de contradicciones carentes de pensamiento» ${ }^{62}$. Como para Kant «el movimiento del actuar»-auténtico término medio de sus postulados ${ }^{63}$ - se entendía como mera acción individual, no podía considerarse auténticamente «eficaz», viéndose obligado a determinar aquella unidad final «o como lo negativo de la autoconciencia, o como algo fuera de ella, como un más allá de su efectividad pero a la vez como un más allá que también es, aunque sólo sea pensado» ${ }^{64}$, en suma, mero «postulado». Porque Hegel concibe el espíritu como acción mediada necesariamente por su apropiación de lo natural y su dimensión intersubjetiva, ahora sí que el «movimiento del actuar» es «eficaz»y «tiene poder sobre el objeto como tal ${ }^{65}$. Lo cual comporta que el «fin final absoluto del mundo», lejos de entenderse como algo abstracto-transcendente, sólo puede consistir en el logro de las condiciones «materiales» exigidas y necesarias para el pleno conocimiento y reconocimiento del yo como un nosotros. Tal es el ámbito de usos, costumbres, instituciones y organismos sociales a través de los que tiene lugar la apropiación del objeto natural y la reconciliación de las conciencias, esto es, el mundo del espíritu objetivo.

En los productos del espíritu objetivo y especialmente en el estado como «realidad efectiva de la idea ética ${ }^{66} \mathrm{es,} \mathrm{pues,} \mathrm{donde} \mathrm{parece} \mathrm{constituirse,} \mathrm{para}$ Hegel, el «mundo» como totalidad ordenada. Ahora bien, esta interpretación de la realidad como proceso hacia la efectuación de la eticidad del estado, ¿es

[60] Kant, KU, § $84(\mathrm{Ak}, \mathrm{V}, 434)$.

[61] Ibid. (Ak, V, 435).

[62] PhG (GW, IX, 332).

[63] «El primer postulado era la armonía de la moralidad y la naturaleza objetiva: el fin final del mundo. El otro, la armonía de la moralidad y la voluntad sensible: el fin final de la autoconsciencia como tal. El primero, pues, la armonía en la forma del en-sí, el segundo en la forma del para-sí. Pero lo que conecta como término medio ambos fines finales extremos es el movimiento del actuar efectivo mismo» (PhG; GW, IX, 328).

[64] PhG (GW, IX, 331).

[65] Ibid.

[66] GPhR § 257 (GW, XIV-1, 201). 
suficiente para comprender y justificar las pasiones, intereses, egoísmos, males y maldades de los acontecimientos humanos y librarnos de la profunda tristeza que nos embarga al contemplar el espectáculo de la historia ${ }^{67}$ ? O bien, a la vista de tales desdichas, ¿no sería más coherente aceptar, con Spinoza, que «la opinión que somete todas las cosas a cierta voluntad indiferente de Dios y que establece que todo depende de su antojo, se aparta menos de la verdad que la opinión de quienes afirman que Dios actúa en todo en orden al bien» ${ }^{68}$ ? Que estos interrogantes no son retóricos, lo prueba sobradamente un pasaje del mismo Hegel:

"Justicia y virtud, injusticia, violencia y vicio, talento y obras, pequeñas y grandes pasiones, culpa e inocencia, gloria de cada pueblo, independencia, fortuna y desgracia de estados y de individuos tienen su significado y valor determinados en la esfera de la realidad consciente, y allí encuentran su juicio y justicia siempre imperfectos. La historia del mundo cae fuera de estos puntos de vista: en ella, aquel momento de la idea del espíritu del mundo que constituye su estadio presente sustenta su derecho absoluto, y el pueblo que lo anima y sus acciones adquieren su plenitud, gloria y fama [...]. Este pueblo es, en la historia del mundo para esa época -y sólo puede hacer época una vez-, el dominante. Contra su derecho absoluto de ser el portador del actual estadio de despliegue del espíritu del mundo, los espíritus de los otros pueblos carecen de derecho y, como aquellos cuya época ya pasó, no cuentan más en la historia del mundo» ${ }^{69}$.

Hay que reconocer abiertamente que, en pasajes como este, Hegel apunta a un punto nuclear en el orden conceptual del sistema: está sosteniendo explícitamente que la historia fáctica (sociopolítica) nunca ofrecerá objetivamente «ningún resultado reconciliador» que «compense»-ni siquiera maquiavélicamente- sus calamidades ${ }^{70}$. Y, en efecto, tan drástica afirmación viene avalada por dos tesis centrales en el sistema. (1) Según la filosofía del derecho, el nivel máximo de integración y reconocimiento de las conciencias se opera bajo la soberanía del estado constitucional moderno, de modo que ninguna institución ni organismo supraestatal -congreso o federación de estados- será nunca capaz de conciliar los conflictos entre las naciones, quedando así la historia del mundo necesariamente abandonada a su triste suerte de conflictos y violencias ${ }^{71}$. (2)

[67] VorlPhG (MPhB, I, 79-80).

[68] Spinoza, Ethica, I, prop. XXXIII, esc. 2.

[69] GPhR, §345, §347 (GW, XIV-1, 275, 276).

[70] «estos acontecimientos, sin exageración retórica, se pueden [...] elevar a la imagen más terrible y aumentar así la sensación de la tristeza más profunda y desconsolada, a la que ningún resultado reconciliador sirve de contrapeso» (VorlPhG; MPhB, I, 80).

[71] Véase mi artículo «¿Hay un derecho a la guerra?» en: M. Alvarez, $M^{a}$.C. Paredes 
Aun cuando pudiéramos concebir una entidad supranacional que incluyera las condiciones exigidas por Hegel para el uso eficaz de la soberanía -algo así como una «federación armada» al modo de Fichte-, o simplemente pensáramos en la meta final como una educación del género humano a la manera de Lessing, seguiría en pie otra razón aún más esencial:

«Dado que este despliegue [efectuación del fin final en el mundo] acaece en el tiempo y, por tanto, como historia, sus momentos singulares y etapas son los espíritus de los pueblos: cada uno de los cuales, en tanto que una determinidad cualitativa, está destinado a cumplimentar sólo una etapa y a efectuar sólo una tarea de la acción total $»^{72}$.

La necesaria temporalización del fin final del espíritu objetivo en el mundo implica a fortiori una sucesión de momentos, de lo cual sólo puede derivarse la «mala infinitud»: el absurdo de poner como meta de lo real algo que -dada la estructura (como máximo) asintótica de la sucesión temporal- nunca será efectivamente real. Justamente la crítica dirigida por Hegel contra los postulados kantianos y la idea de progreso indefinido ${ }^{73}$. De jure, pues, no se puede concebir la realización del fin final -reconciliación intersubjetiva plena- en la historia del espíritu objetivo, ya que ésta no va más allá de momentos de «reconciliación relativa» (estados y pueblos), ninguno de los cuales puede aspirar a ser la epifanía del espíritu en el tiempo ${ }^{74}$. Por consiguiente, o bien el espíritu y la dinámica de reconciliación puesta por su estructura constitutiva va más allá de la vertiente sociopolítica, o bien tanto él como su productos configuran una dinámica auto-contradictoria. Si lo primero, el «orden del mundo» no podrá coincidir sin más, como parecía prima facie, con el espíritu objetivo y, por tanto, habrá que elevarse a otra perspectiva sobre lo real; si lo segundo, simplemente no habría «mundo». Pues bien, para Hegel el «espíritu pensante»,

(eds), Derecho, Historia y Religión. Interpretaciones sobre la filosofía del derecho de Hegel, Ediciones Universidad de Salamanca, 2013, pp. 155-169.

[72] Enz. $\$ 549$ (GW, XX, 524). Más adelante se insiste en ello: «El espíritu del pueblo contiene la necesidad natural y se halla en una existencia exterior. La sustancia ética infinita en sí es para sí una sustancia particular y limitada, y su lado subjetivo está sujeto a contingencia: [es] costumbre inconsciente y conciencia de su contenido como algo temporalmente presente y en relación a una naturaleza exterior y mundo» (Enz. $\$ 552$; GW, XX, 530).

[73] Enz. \$62 (GW, XX, 100).

[74] Kojève, en su obra ya clásica sobre la Fenomenología del Espíritu (Introduction à la lecture de Hegel, París, Gallimard, 1947), para poder defender tal epifanía, ha tenido que alterar radicalmente el texto hegeliano en estos dos puntos: poner como finalidad de la historia un «estado homogéneo universal» y sostener que tal meta se realiza efectivamente en la sociedad postindustrial. De hecho, tal lectura conserva lo esencial de la operación llevada a cabo por el hegelianismo político de izquierdas el siglo anterior, especialmente el materialismo histórico de raíz marxista. 
efectivamente, no queda cautivo de la temporalidad histórica sino que, desde ella y ante su inconsistencia, se eleva a lo «eternamente real»:

«Pero el espíritu pensante en la eticidad es el que supera en sí la finitud que tiene en cuanto espíritu del pueblo en un estado y sus intereses temporales -en el sistema de las leyes y costumbres-, y es el que se eleva al saber de sí en su esencialidad [...]. El espíritu pensante de la historia del mundo, en tanto que a la vez se despoja de aquellas limitaciones de los espíritus particulares de los pueblos y de su propia mundanidad, aprehende su universalidad concreta y se eleva al saber del espíritu absoluto en tanto que verdad eternamente real en que la razón sabia es libre para sí, y en que la necesidad, la naturaleza y la historia están sirviendo sólo a su revelación y son los vasos de su gloria» ${ }^{75}$.

En esta perspectiva, la meditación filosófica sobre lo efímero de los imperios y reinos de este mundo ${ }^{76}$ cumple el papel -en perfecta sintonía con la tradición antigua- de mostrarnos que sic transit gloria mundi y que vanitas vanitatis, omnia vanitas. ¿A qué sabiduría nos eleva la caducidad del espíritu objetivo? ¿Hay algún tipo de reconciliación y reconocimiento en que se juega, más esencialmente aún que en la dimensión sociopolítica, la dinámica de escisión y unificación que caracteriza el espíritu finito? ¿En qué medida tal saber y reconciliación en lo «eternamente real» supera la sucesión temporal del pseudo-progreso indefinido? Claramente tales interrogantes apuntan al ámbito de la religión y de la teología, donde finalmente en Dios «todo enigma del mundo, todas las contradicciones del pensamiento, todos los dolores del sentimiento se resuelven; la región de la verdad eterna y del descanso eterno, la verdad absoluta misma ${ }^{77}$.

El tránsito del espíritu objetivo a la perspectiva religioso-teológica en la Enciclopedia se efectúa conceptualmente, según el texto antes citado, cuando el «espíritu pensante» reflexiona sobre la eticidad superando la «limitación de los espíritus particulares de los pueblos». Explicitemos este paso y su resultado:

1. Recordemos la vinculación entre la nota al $\$ 50$ y al $\$ 552$ de la Enciclopedia: si hay un camino para elevarnos del «mundo» a Dios, no puede

[75] Enz. \$552 (GW, XX, 530).

[76] «Lo que más nos puede apesadumbrar es que la figura más rica y la vida más bella tienen su ocaso, y que caminan entre las ruinas de lo más excelente. La historia nos arrebata lo más noble, lo más bello por lo que nos interesamos: las pasiones lo han hundido, es caduco. Todo parece pasar y nada permanece. Todo viajero ha sentido esta melancolía. ¿Quién no ha podido estar entre las ruinas de Cartago, Palmira, Persépolis, Roma sin que le provoquen consideraciones sobre el carácter efímero de los imperios y de los hombres, sin que le provoquen dolor por aquella vida tan rica y potente?» (VorlPhG; MPhB, I, 34-35).

[77] Vorlesungen über die Philosophie der Religion [VorlPhRel], Manuskript (MPhB, I, 3-4). 
partir simplemente de lo natural (mecánico ni teleológico), sino sólo del espíritu. Pero el espíritu finito está ordenado a la eticidad, y ésta comporta que la dispersión y escisión de lo meramente individualempírico es superada por estructuras objetivas de universalidad creciente en las que finalmente la subjetividad encuentra su sentido, tanto en lo referente a su vertiente cognoscitiva -paso de la certeza sensible a la ciencia- como práctica -paso de la lucha a muerte al perdón (estado racional). Por tanto, «en el espíritu ético se ha cumplido efectivamente la purificación del saber [finito] respecto a la opinión subjetiva y también de la voluntad respecto al egoísmo del deseo» ${ }^{78}$.

2. Tal experiencia purificadora de reconciliación espiritual es una auténtica conversio morum o $\mu \varepsilon \tau \alpha$ vóı $\alpha$ en que «los yoes desisten de su existencia contrapuesta [...] y, en la completa exteriorización y en su contrario, [cada uno] tiene la certeza de sí mismo: es el Dios que aparece en medio de ellos» ${ }^{79}$. Por tanto, si ponemos entre paréntesis los componentes históricamente condicionados de la eticidad y nos centramos en su momento de plenitud supraindividual, se entiende la afirmación de Hegel: «sólo a partir de la eticidad y desde ella se hace consciente la idea de Dios como espíritu libre» ${ }^{80}$.

3. Dios, en tanto que espíritu, no puede concebirse como la abstracción metafísico-racional de la tradición: sea la substancia «absoluta» pero muerta y sin vida de Spinoza, sea el «ideal de la razón pura» indeterminable y vacío de todo contenido de Kant. Lejos de consistir en la identidad de una igualdad abstracta consigo misma, Dios es «la identidad que tanto es eternamente en sí como está regresando y ha regresado a sí» ${ }^{81}$. El ser divino, en su eterno salir de sí y volver a sí, «no es sólo una esencia que se conserva en el pensamiento, sino que también es su darse en tanto que aparece, se revela, se objetiva» ${ }^{82}$, pues «el espíritu que no se manifiesta, no es espíritu» ${ }^{83}$. Las formas de aparecer (Erscheinungen) o manifestaciones (Manifestationen) del Absoluto ${ }^{84}$ son precisamente los dos lados del «mundo»: la naturaleza y el espíritu finito. Con lo cual se alcanza la perspectiva cosmo-teológica absoluta: que «el despliegue de Dios en sí y el despliegue del universo

[78] Enz. $\$ 552$ Anm. (GW, XX, 531).

[79] $\mathrm{PhG}(\mathrm{GW}, \mathrm{IX}, 362)$.

[80] Enz. $\$ 552$ Anm. (GW, XX, 531).

[81] Enz. $\$ 554(\mathrm{GW}, \mathrm{XX}, 542)$.

[82] VorlPhRel, 1824 (MPhB, I, 35).

[83] VorlPhRel, 1824 (MPhB, I, 37).

[84] Enz. $\$ 577$ (GW, XX, 571). 
no son tan absolutamente diferentes [...]; este círculo -el hacerse de la vida divina- es lo mismo que el de la vida del mundo, aunque esta vida es sólo manifestación mientras que aquella es lo eterno» ${ }^{85}$.

Dado que «el despliegue de Dios en sí» se refleja en «la vida del mundo», se entiende que el desarrollo histórico del espíritu finito no sólo obedezca al dinamismo del reconocimiento intersubjetivo (historia sociopolítica), sino que consista más esencialmente aún en la elevación de la conciencia a Dios para, comprendiéndolo y haciéndose en cierto modo uno con él, alcanzar aquel «fin final que no tiene ningún otro más allá de él»: «ocuparse de lo eterno» ${ }^{86}$. Tarea esta que, además se constituir subjetivamente la «verdadera dignidad» del ser espiritual y el «domingo de su vida» ${ }^{87}$, de algún modo manifiesta también objetivamente (en el orden del tiempo) el regreso (eterno) de Dios a sí mismo. Lo Absoluto, pues, más allá de la historia del espíritu objetivo (eticidad del estado racional), se muestra plenamente a sí mismo en la intelección que la conciencia alcanza de él: tal es el ámbito del «espíritu absoluto» y de su despliegue como historia artístico-religiosa y filosófica de la humanidad. Sólo

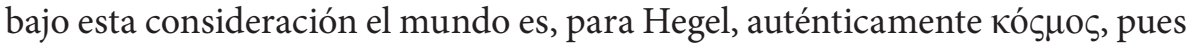
es mediante la religión y la filosofía que la sucesión del tiempo (lineal) toca (tangencialmente) la eternidad (circular) y así ambos se hacen en cierto modo uno, salvándose el mundo de su abandono a la mala infinitud. La naturaleza manifestativa del Absoluto es un volle me tangere que, lejos de perderse en el desideratum inalcanzable del progreso indefinido, aparece efectivamente en la historia. Y aparece bajo dos formas de expresar la misma verdad: bajo la forma representativa de la conciencia religiosa que culmina en el cristianismo como religión de la Encarnación de Dios, y bajo la forma filosófico-conceptual del propio el sistema hegeliano.

Así pues, en el cristianismo y en la reconstrucción filosófica de su verdad por la dialéctica hegeliana del concepto, Dios se ha manifestado y se manifiesta plenamente al mundo. Frente al dolor, tristeza e insatisfacción de una historia sociopolítica cuya plenitud, en todo caso, no puede ir más allá de la esfera del estado, la filosofía teológica, como reconciliación de lo finito con lo infinito, aporta «no un goce en la moralidad, en la eticidad o en la conciencia moral, sino un goce fuera del cual no hay nada superior, relación con Dios mismo» ${ }^{88}$, esto es, "participación en la serenidad desapasionada del conocimiento del puro

[85] VorlPhRel, Manuskript (MPhB, I, 141).

[86] VorlPhRel, Manuskript (MPhB, I, 4).

[87] «Todos los hombres tienen pues una conciencia de Dios, de la substancia absoluta como de la verdad [...], y consideran la ocupación, el saber y el sentir de Dios como su vida más elevada, su verdadera dignidad y como el domingo de su vida» (Ibid.).

[88] VorlPhRel, 1827 (MPhB, III, 245). 


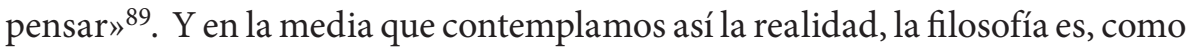
entre los antiguos, la consolatio que reconcilia al sabio con el mundo presente:

«Conocer la razón como la rosa en la cruz del presente y así gozarse en ello, esta intelección racional es la reconciliación con la realidad que la filosofía otorga a quienes alguna vez ha acaecido la exigencia interna de concebir y de conservar en lo que es sustancial la libertad subjetiva al mismo tiempo que mantenerla no en lo particular y accidental, sino en lo que es en y para sí»»0.

Por tanto, sólo si pensamos la realidad y la historia de modo que el dinamismo del espíritu objetivo se subsuma en el desarrollo del espíritu absoluto, el «mundo» aparece como «orden» en el sentido pleno de la expresión: кó $̧ \mu \circ \varsigma$

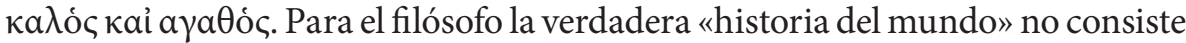
en la simple sucesión empírica de los hechos, ni tampoco sólo en su orientación política hacia la eticidad del estado, sino en que, a través del desarrollo del arte, la religión y la filosofía, lo Absoluto se revela. Sólo en este sentido la historia del mundo es auténtica epifanía de lo divino:

«La filosofía debe ayudar a la intelección de que el mundo real es tal como ha de ser, que la voluntad racional, el bien concreto es de hecho el poder absoluto que se realiza. El bien verdadero, la razón divina universal es también el poder de realizarse. Este bien, esta razón en su representación más concreta es Dios [...]. Dios gobierna el mundo; el contenido de su gobierno, el cumplimiento de su plan es la historia del mundo [...]. A la luz de esta idea divina, que no es meramente un ideal, desaparece la apariencia del mundo como un acontecer absurdo y necio. La filosofía quiere conocer el contenido y realidad de la idea divina, y justificar la despreciada realidad, pues la razón es percepción de la obra divina»191.

Si la mundanización efectiva de lo real tiene lugar cuando el filósofo accede a la idea divina y desde ella entiende que, frente a «la apariencia del mundo como un acontecer absurdo y necio», en verdad todo acaece de acuerdo con el orden eterno de la divinidad, ¿no coincide finalmente Hegel con la doctrina esbozada por Spinoza en el libro V de la Ética? También el sabio spinozista, al elevarse al tercer género de conocimiento, sabe que «nuestra mente, en tanto que se conoce y conoce el cuerpo sub specie aeternitatis, tiene en esto necesariamente un conocimiento de Dios y sabe que está en Dios y que se concibe por Dios ${ }^{92}$, y este saber le permite entender que, frente a las quejas y lamentaciones

[89] WL (GW, XXI, 20).

[90] GPhR (GW, XIV-1, 15-16).

[91] VorlPhG (MPhB, I, 77-78).

[92] SpInoza, Ethica, V, prop. XXX. 
del hombre común, «las cosas han sido producidas por Dios con máxima perfección, pues se han seguido necesariamente de la más perfecta naturaleza» ${ }^{93}$.

Sin duda, formalmente al menos, las posiciones de Hegel y Spinoza no están demasiado alejadas. Y también en ambos casos, la comprensión del mundo sub specie aeternitatis procura la máxima perfección humana y la vida más plena: si en un caso el "gozarse en la idea eterna que existe en y por sí misma»" ${ }^{94}$ nos permite «llegar a ser dueños de aquella oposición [finito, infinito] $»^{95}$ superando la alienación y desdicha de la conciencia, en el otro «el amor intelectual de Dios que surge del tercer género de conocimiento» ${ }^{96}$ produce aquella beatitud «que no es el premio de la virtud, sino la virtud misma» ${ }^{97}$. No es así de extrañar que Hegel, en el balance de su exposición de la filosofía spinozista, pueda afirmar elogiosamente que «no hay ninguna moral más pura ni elevada que la de Spinoza [...] pues [su pensamiento] es el regreso del espíritu a Dios» ${ }^{98}$. Lo cual justificaría, en sentido a la vez moral y metafísico, su «acosmismo»:

«Spinoza reivindica además el modo de conocimiento verdadero -pensarlo todo sub specie aeterni- en conceptos absolutamente adecuados, es decir, en Dios. El hombre ha de reconducirlo todo a Dios, Dios es uno en todo; así el spinozismo es acosmismo" $"$.

Pero si en esta acepción Spinoza es «acosmista», dada la similitud con la posición del mismo Hegel, se entiende que éste pueda también caracterizar su filosofía de forma semejante, si no terminológica, al menos descriptivamente:

«Pero [la filosofía] no es de hecho ninguna sabiduría del mundo, sino un conocimiento de lo no-mundano; no es ningún conocimiento de la existencia externa, del existente empírico, de la vida o del universo formal, sino que es conocimiento de todo aquello que es eterno, de aquello que Dios es y que desarrolla su naturaleza en tanto que se manifiesta $»^{100}$.

Ahora bien, más allá de la coincidencia de que tanto Spinoza como Hegel consideren que sólo la visión filosófica de la vinculación del mundo con lo eterno hace de aquél кó $\mu_{0}$ os, si pasamos a considerar en concreto el «orden del mundo»

[93] Ibid., I, prop. XXXIII, esc. II.

[94] Enz. \$577 (GW, XX, 571).

[95] VorlPhRel (MPhB, I, p. 120).

[96] SpInoza, Ethica, V, prop. XXXIII.

[97] Ibid., prop. XLII.

[98] VorlGPh (TWA, XX, 191).

[99] Ibid.

[100] VorlPhRel, 1824 (MPhB, I, 33-34). 
que se piensa en cada caso, las diferencias son tales que justifican sobradamente que desde un «mundo» el otro aparezca más bien como «a-cósmico». Un pasaje de Hegel evidencia claramente cómo el acuerdo en la mayor se convierte en desacuerdo en la menor y, por tanto -dado que la verdad no radica tanto en lo universal como en lo concreto-, en una disparidad radical de perspectivas:

«Esta reconciliación es la filosofía: la filosofía en tanto que es teología. Ella expone la reconciliación de Dios consigo mismo y con la naturaleza, que la naturaleza (el ser-otro) es en sí divina y que el espíritu finito en sí mismo es, en parte, el elevarse a esta reconciliación, pero en parte llega a esta reconciliación en la historia del mundo» ${ }^{101}$.

A partir de la premisa común de que, en la intelección sub specie aeternitatis, se supera la contraposición entre extensio-naturaleza y cogitatio-espíritu en tanto que ambas son Erscheinung o expressio de la divinidad, Hegel extrae dos conclusiones que resultarían a todas luces insostenibles para Spinoza: (1) que ello es también la reconciliación de Dios consigo mismo y (2) que el espíritu finito alcanza tal reconciliación en la historia. Para que tales afirmaciones resulten consistentes es preciso substituir la comprensión metafísica tradicional de Dios como substancia por la de Dios como espíritu. Tal substitución, al introducir como esencial a la divinidad el movimiento del en sí al para sí, permite sostener a Hegel que: (1) la manifestación de Dios pasa por el mundo (naturaleza y espíritu finito), que así se ve de algún modo implicado en el hacerse eterno de Dios; (2) que en el orden del mundo, por ser temporal, la reconciliación del espíritu (consigo mismo y con Dios) no puede acaecer más que si hay algún momento privilegiado en que Dios se manifieste tal como es en y para sí. Tal irrupción de Dios en la historia del mundo comporta la ruptura con el esquema de la temporalidad lineal y de la causalidad mecánica de la serie spinozista de los modos -en último término el universo homogéneo e isótropo de la física moderna-, para situarse en una temporalidad «cualitativa» que orienta y da un sentido al tiempo y al mundo:

1. La encarnación de Dios en Cristo, en tanto que revelación fáctica del espíritu y su dinamismo de reconciliación, marca un "antes» y un «después» absolutos en la historia, de modo que el futuro intramundano sólo puede orientarse a realizar cuanto allí se ha anticipado.

2. Pero mientras que en el orden intelectivo la filosofía (hegeliana) explicita definitivamente la naturaleza del espíritu y así consuma (en la idea) la reconciliación entre lo finito y lo eterno -la Lógica como clausura del despliegue del concepto-, distinta es la situación en el orden in-

[101] VorlPhRel, 1827 (MPhB, III, 269). 
tersubjetivo de las relaciones sociales. Aquí, dada la constitución del espíritu finito -distensión espaciotemporal de individuos y pueblos-, siempre resta «el impedimento de algo abstracto que no se ha liberado para el concepto» ${ }^{102}$, de modo que, al no producirse aquella clausura, la historia sociopolítica queda abocada a la mala infinitud. Por eso precisamente, en el ámbito del espíritu objetivo «es necio imaginarse que alguna filosofía pueda ir más allá del mundo presente» ${ }^{103} \mathrm{y}$ «la filosofía pinta en sus tonos grises una figura de la vida ya pasada que, en su penumbra, no se deja rejuvenecer sino sólo conocer» ${ }^{104}$.

3. No obstante, el espíritu objetivo también es fruto del espíritu y, por tanto, despliegue de su dinamismo por reconocer al otro como igual a sí mismo -mensaje avanzado Cristo y tesis central del sistema filosófico. Por ello no puede quedar totalmente abandonado al curso azaroso del tiempo, pues «el espíritu divino ha de penetrar inmanentemente lo mundano, y así la sabiduría hacerse allí concreta y su legitimidad determinarse en el mismo mundo; las configuraciones de la eticidad constituyen esta inhabitación concreta» ${ }^{105}$. De ahí el papel que juega la idea del estado en la historia: como tendencia motriz implícita en el desarrollo de las formaciones políticas y como cumplimiento (relativo) en la forma constitucional del tiempo presente. Así, aunque la historia política del mundo nunca pueda superar la guerra entre los pueblos y postergue ad infinitum la realización del Reino de Dios en la tierra, no obstante lleva también el sello de lo divino en la lucha de los individuos por realizar, al menos, un estado reconciliado ${ }^{106}$.

En suma, hay «mundo» porque la totalidad del tiempo se ordena en función de dos momentos de validez trans-histórica y una tarea intra-histórica: el momento del anuncio del Reino de Dios y su cumplimiento singular en Cristo, y el momento del reconocimiento conceptual del espíritu absoluto en la filosofía hegeliana; la tarea política para que «el espíritu llegue a ser lo que verdaderamente es, que haga objetivo aquel saber, que lo haga efectivo en un mundo existente» ${ }^{107}$. Desde esta perspectiva histórico-espiritual, el modo de entender lo real por parte de Spinoza -la disposición de los modos- sólo puede

[102] GPhR, Vorrede (GW, XIV-1, 15).

[103] Ibid.

[104] Ibid. (GW, XIV-1, 16).

[105] Enz. \$552 Anm. (GW, XX, 535).

[106] En palabras de Theunissen: «La esfera del espíritu objetivo, en que también cae el estado, se encuentra empero subordinada a la esfera del espíritu absoluto. Hegel no sólo separa el Reino de Dios del estado, sino que lo pone mucho más allá de él: en la región frente a la cual fundamentalmente nada superior puede darse» (Op. Cit., p. 373).

[107] VorlPhG (MPhB, I, 74). 
parecer algo verdaderamente «in-mundo»: en lugar de la conciencia como abertura a la alteridad, el hombre concebido como un «autómata espiritual» ${ }^{108}$; en lugar de la libertad como principio de auto-actividad, la mecánica inercial de afectos y pasiones ${ }^{109}$; en lugar del reconocimiento intersubjetivo como motor de socialización, una comprensión de la sociedad basada en el apetito e instinto de conservación ${ }^{110}$; en lugar del estado como racionalidad y eticidad correctoras de las escisiones de la sociedad civil, una doctrina del gobierno basada en el mero sistema de necesidades ${ }^{111}$; en lugar de subrayar el momento especulativo y a la vez comunitario de la religión, su reducción a simple mecanismo imaginativo causante de odios y discordias ${ }^{112}$. En pocas palabras, «la substancia absoluta de Spinoza aún no es el espíritu absoluto, y con todo derecho se exige que Dios ha de ser determinado como espíritu absoluto» ${ }^{113}$.

\section{VI}

Wolff, Platner o Maimon respondían al «acosmismo» de Spinoza defendiendo el orden físico-teleológico y moral-teológico del mundo (modelo timeico) a partir de su reformulación lebiniziana. Pero tal «restauración» era, en su literalidad, imposible justamente a causa de Spinoza, pues en él coinciden las dos causas determinantes del hundimiento de los «dos libros» del universo tradicional: la nueva ciencia físico-matemática con su reducción de la naturaleza a mera extensión desprovista de cualidades y la crítica bíblica con su cuestionamiento de la revelación ${ }^{114}$. El «mundo acósmico» de Spinoza es el modelo resultante de este doble «desencantamiento» moderno: desaparición de toda relevancia y significatividad moral-teleológica -aunque sólo sea simbólica- de la natura naturata y consiguiente uniformización de lo existente (extensio o cogitatio) en un único ordo geométrico (homogéneo e isótropo) estrictamente

[108] «Pero que yo sepa [los antiguos] nunca concibieron, como nosotros aquí, que el alma actuara según leyes estrictas y casi a la manera de un autómata espiritual» (SPINOzA, TIE, § 85).

[109] «Un afecto no puede ser reprimido ni suprimido sino por medio de otro afecto contrario, y más fuerte que el que ha de ser reprimido» (SpINozA, Ethica, IV, prop. 7).

[110] «Pero los hombres son conducidos más por el deseo ciego que por la razón, de aquí que la potencia natural de los hombres (o derecho) debe definirse no por la razón, sino por cualquier apetito que los determina a actuar y que los fuerza a conservarse» (SPINOzA, TP, cap. II, §5).

[111] «Cual sea el mejor régimen para un estado se sabe fácilmente a partir del fin de la sociedad civil: no es otro que la paz y la seguridad de la vida» (Ibid., cap. V, § II).

[112] «La religión no se reduce a la caridad, sino a difundir discordias entre los hombres y a propagar el odio más funesto, que disimulan con el falso nombre de celo divino y fervor ardiente» (SPINOZA, TTP, cap. VII).

[113] Enz. \$50 Anm. (GW, XX, 89).

[114] Véase al respecto mi artículo: «L'altre origen de la Modernitat: el llibre de l'Escriptura» en Convivium, Universitat de Barcelona, n² 20, 2007, pp. 91-111. 
determinista. En la medida que Hegel introduce un orden cualitativo que, anulando la linealidad de la sucesión temporal indefinida, da sentido (éticopolítico, religioso y filosófico-teológico) a la realidad en tanto que manifestación del hacerse eterno de Dios, se opone radicalmente a Spinoza ${ }^{115}$ y ciertamente se «aproxima» al antiguo modelo timeico de la «significatividad» del mundo.

Ahora bien, tal aproximación es sólo formal, dado que la «cosmicidad» del «mundo» hegeliano no radica ya en una pretendida significatividad (teleológico-moral) de la naturaleza por sí misma, pues lo natural sólo puede determinarse conceptualmente como la «negación necesaria» para que el espíritu (tanto finito como infinito) lleve a término su mediación consigo mismo. Frente

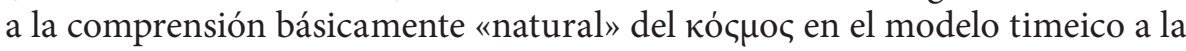
que aún apelaban Wolff, Platner y Maimon, Hegel instaura una ordenación histórico-espiritual como lugar de encuentro, a la vez epifánico (Cristo, filosofía) y proyectivo (tarea ético-política), entre tiempo y eternidad. Por ello, ya no es la contingencia de los movimientos naturales, ni tampoco la supuesta disposición teleológica de los seres -en suma, el ciclo natural como imitación sublunar de lo divino-, lo que constituye el verdadero «orden del mundo», sino sólo su «historia» (sociopolítica y religioso-filosófica) en tanto que realización del espíritu absoluto.

Los dos grandes constructores de «mundo» en la antigüedad, Platón y Lucrecio, antes de adentrarse en sus narraciones cosmológicas, invocaban la ayuda

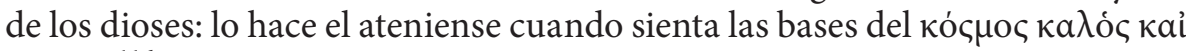
a $\alpha \boldsymbol{\theta} \dot{o} \varsigma^{116}$, lo hace el latino cuando expone poéticamente la acosmicidad de la sola materia en movimiento ${ }^{117}$. Tanto Hegel como Spinoza prescinden de tal preámbulo retórico para situar su discurso en el ámbito exclusivo de la cienti-

[115] «Como Fichte, también Hegel está impresionado por la crítica de Jacobi al espinosismo: el monismo metafísico y metodológico necesariamente mecánico, determinista, nihilista; es incompatible con la certeza vivida de individuos vivos, determinándose libremente, racionales de forma irreductible. Considerada desde esta perspectiva, la problemática del idealismo alemán consiste en mediatizar sus convicciones monísticas con su también profundo compromiso con la realidad de individuos libres» (B. BrowmaN, «Kraft und Verstand» en Hegels Phänomenologie des Geistes. Ein kooperativer Kommentar zu einem Schlüsselwerk der Moderne (K. Vieweg y W. Welsch edts.), Frankfurt, Suhrkamp, 2008, p. 155.

[116] «También nosotros, al disponernos a discurrir sobre el todo, sobre cómo se generó o si es ingénito, si no somos unos insensatos, tendremos que invocar a los dioses y a las diosas y rogarles que cuanto digamos sea conforme a sus pensamientos y también a los nuestros. Sea esta, pues, nuestra invocación a los dioses» (Platón, Timeo, 27c).

[117] «Madre de los Enéadas, goce de los hombres y los dioses, Venus nutriente [...]; porque tú eres quien gobiernas la naturaleza [...], deseo que seas mi compañera para escribir el poema que, sobre la naturaleza de las cosas, me atrevo a componer para nuestro Memmio» (LuCReCio, De natura rerum, I, 1, 22-26). 
ficidad demostrativa (Wissenschaft, scientia intuitiva). Ciertamente la apelación de los antiguos a los dioses no es necesariamente señal de piedad o devoción, como prueba el caso de Lucrecio; ni tampoco su ausencia es señal de ateísmo en los modernos, como muestra al menos el caso de Hegel. Pero la presencia y ausencia de aquella invocación, en lo que tiene de signo de prudencia por parte de nosotros los mortales, sí significa algo hermenéuticamente relevante: que los antiguos tenían quizá más clara conciencia que los modernos de la difícil y aventurada labor «cosmética» de la filosofía parar responder a nuestro anhelo de «mundo». Y, en efecto, la aceptación de esta dimensión "cosmetizadora» del discurso filosófico reduciría las pretensiones totalizadoras del Begriff o de

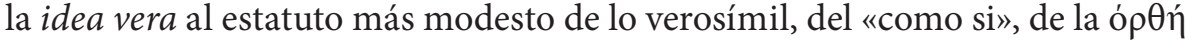
$\delta o ́ \xi \alpha$, de la creencia razonable ${ }^{118}$. Precisamente por esto, en la discusión sobre el «orden del mundo» y como contrapunto a los dos modelos aquí analizados, sería oportuno reconsiderar la posición de uno de los pocos autores que, entre los modernos, mantiene una prudencia semejante a los antiguos: Kant y su «novela de la historia». Al menos sería conveniente ocuparse de su peculiar «mundanización als-ob» para quienes, como él, piensen que «yo, pobre hijo de la tierra, no estoy en absoluto organizado para el lenguaje de Dios de la razón intuitiva» ${ }^{119}$.

[118] Tal es, en efecto, el modo en que Platón presenta su narración cosmológica: «En efecto, Sócrates, si resulta en muchos temas referentes a los dioses y al origen de todo somos incapaces de presentar razonamientos coherentes y precisos en todos los puntos, no tendrías que sorprenderte. Con que consigamos hacerlos tan verosímiles como cualquier otro, ya tendríamos que felicitarnos, recordando que tanto yo, que hablo, como vosotros, que hacéis de jueces, tenemos una naturaleza humana y, consiguientemente, nos basta con el relato que tenga verosimilitud sin buscar nada más allá» (Platón, Timeo, 29c).

[119] Kant a Hamann, 6.IV.1774 (Ak, X, 156). 
